\title{
Pandemic meets epidemic: Co-location of COVID-19 and drug overdose deaths in the United States
}

\author{
Navya Tripathi* and Nancy Hardt ${ }^{\dagger}$
}

\begin{abstract}
Drug overdose deaths (DOD) in the last two decades have increased over 300 percent. In 2019 alone, 71,000 deaths represented a 7\% increase from the previous year. According to recent data released by the Center for Disease Control and Prevention (CDC), 81,230 overdose deaths occurred in the United States from June 2019 to May 2020, the highest number of DOD recorded in a 12-month period. Early 2020 saw the spread of the COVID-19 pandemic in the United States, which CDC suggests has amplified the previously alarming rise in drug-related mortalities. A hot spot analysis of COVID-19 and DOD rates, as well as a spatial correlation between the two datasets at the state level on a monthly time step, showed a significant increase in DOD during the COVID-19 pandemic. This study, conducted for the period of March through July 2021 , showed a spatial correlation between the two types of mortalities in the initial months of 2020. Furthermore, the hot spots for both types of mortalities were concentrated in the northeastern states. The COVID-19 mortalities shifted southeast in July 2020, but DOD data was unavailable for further analysis. Since DOD are a leading contributor to preventable deaths, the results of the study may help focus the efforts of effective and innovative programs to reduce substance use disorder and related mortality through increased access to treatment. During the pandemic, access to such facilities was reduced.
\end{abstract}

Key Words Spatial correlation; hot spot analysis; 2020; census regions.

\section{INTRODUCTION}

Drug overdose deaths ${ }^{\mathrm{a}}(\mathrm{DOD})$ in the United States have gained national attention, and in 2018, a national epidemic was declared. With more than 800,000 DOD in the United States since 1999, the rate of DOD has dramatically increased (Centers for Disease Control and Prevention, CDC, 2021a). According to the CDC, in 2019 there were 71,000 DOD reported, a 7\% increase over 2018, and 2020 saw a further increase in overdose deaths. According to the data released by the CDC National Center for Health Statistics, approximately 68,446 deaths occurred in the first three quarters of 2020 compared with 52,591 deaths over the same time period in 2019 (CDC, 2021b), which represents a 26\% increase in DOD in 2020 over 2019.

Health-care experts have speculated on reasons for the increase of overdose deaths in recent years, with leading causes being the increased availability of drugs (Cicero et al.,

a"Drug Overdose Deaths" and "Drug Overdose Mortalities" have been used interchangeably in this paper.
2014; Mann, 2021) and reduced awareness and public education on substance use disorder (RHIhub, 2021), as well as increased mental illness in the United States due to depression and anxiety (Baumgartner \& Radley, 2021). Distressed individuals often self-medicate in their attempts to gain relief, especially in the absence of mental health care. Thus, the increase in DOD in 2020 could be due to the COVID-19 pandemic affecting both the social and economic aspects of peoples' lives (Carrasco, 2021; Czeisler et al, 2020; Mann, 2021; Stephenson, 2020). Decreased access to medical and social support during the pandemic may also be one of the contributing factors to the increase observed (Mann, 2021; Volkow, 2020; Weiner, 2020).

Drug overdose deaths are unevenly distributed across the United States. Specific geographic areas, such as parts of West, the Midwest, South, and Northeast, have reported higher mortalities due to substance abuse than other areas (DHEC, 2020; Tripathi, 2019), with rural areas more heavily affected (Ghertner \& Groves, 2018; Wagner et al., 2019). Similarly, COVID-19 mortalities affected the nation inequitably,

Correspondence to: Navya Tripathi, Senior, Buchholz High School, 5510 NW 27th Ave, Gainesville, FL 32606, USA. E-mail: Navya.Tripathi@gmail.com

To cite: Tripathi, N., \& Hardt, N. (2021). Pandemic meets epidemic: Co-location of COVID-19 and drug overdose deaths in the United States. Journal of Community Safety and Well-Being, 6(4), 174-178. https://doi.org/10.35502/jcswb.216

@ Author(s) 2021. Open Access. This work is distributed under the Creative Commons BY-NC-ND license. For commercial re-use, please contact sales@sgpublishing.ca.

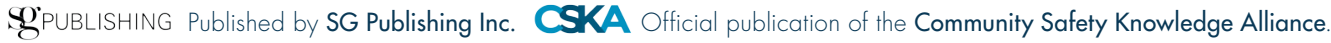


with areas in the Northeast, New Orleans, and Detroit experiencing higher mortalities during the first wave before the southern region was hit during subsequent waves (Johnson et al., 2021). According to the American Medical Association Issue Brief (2021), “Every state has reported a spike or increase in overdose deaths or other problems during the COVID pandemic." This study aims to determine whether there is any spatial correlation between the drug overdose deaths and deaths due to the COVID-19 pandemic from the months of March to July 2020.

Substance abuse disorder is a contributor to preventable deaths. The results of the study may help focus the efforts of effective and innovative programs to reduce substance use disorder and related mortality through increased access to treatment. During the pandemic, access to treatment facilities was reduced (Volkow, 2020).

\section{METHODS}

The study was done using state-level data. The March-July 2020 COVID-19 data and the January-July 2020 drug overdose data were downloaded from the CDC National Vital Statistics System (NVSS) website (NVSS, 2021). The total population data for each state was downloaded from the Census website to calculate the crude mortality rates. To study co-location between the two datasets, a Geographic Information System (GIS) was used. The crude mortalities were spatially joined with the state data using GIS software, ArcGIS Pro (ESRI). After data preprocessing and preparation, ArcGIS Pro software was used to create a map of statistically significant hot and cold spots for each dataset on a monthly basis. Getis-Ord $\mathrm{Gi}^{*}$ statistic (ESRI) was used to find $z$-scores and $\mathrm{p}$ values to identify where features with either high or low values clustered spatially. Spatial and temporal correlations (if any) were studied between the two datasets for each month from March through July 2020 using the Band Collection Statistics tool in ArcGIS Pro. States and regions with the highest DOD during the COVID-19 months were identified. The results were also analyzed by Census region-West, Midwest, Northeast, and South.

\section{RESULTS}

Early in the year, there was an overall increase in drug overdose mortality rates in some states, but not all, when compared with the 2019 data. By July 2020, as the pandemic progressed, almost all states showed an increase in drug overdose mortality compared with the same months in 2019. In other words, even states that were showing success in their efforts to reduce overdose deaths started experiencing an increase in DOD as the pandemic continued. Figure 1 shows the steady increase in the number of states experiencing higher DOD in 2020 as the COVID-19 pandemic progressed.

\section{Regional Analysis}

The mortalities under each dataset were analyzed to see whether the states that were hit hard by the pandemic also experienced higher DOD. At the national level, five of the top ten locales that experienced higher COVID-19 mortalities also experienced higher drug overdose mortalities. Those
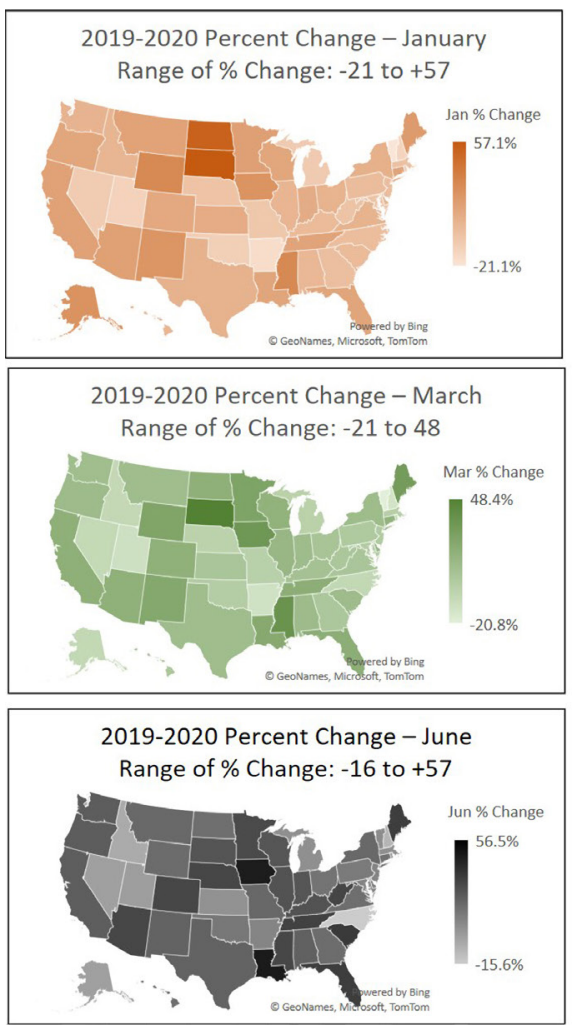

2019-2020 Percent Change - February Range of \% Change: -27 to +43
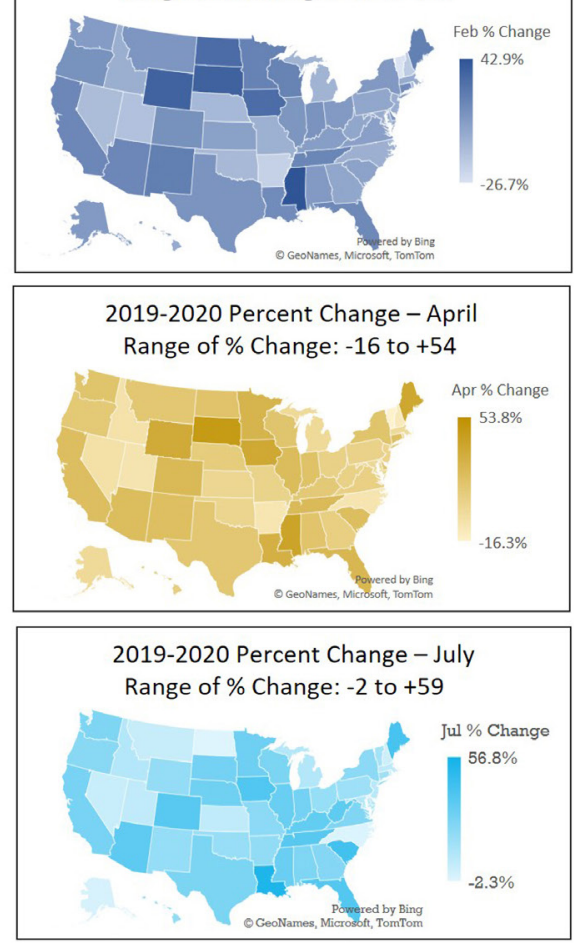

\section{DRUG MORTHLITY ANALYSIS 2019-2020 PERCENT CHANGE - MONTHLY}

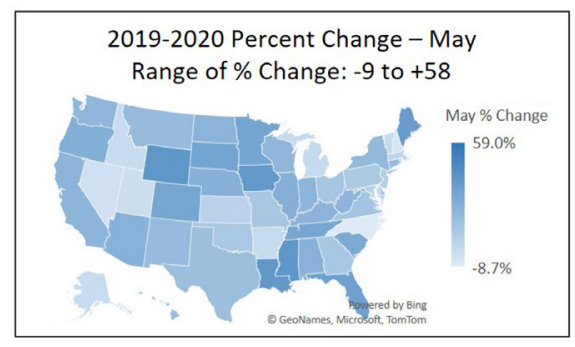

FIGURE 1 Monthly percent change in drug overdose mortalities 2019-2020 
locales were District of Columbia, Maryland, Pennsylvania, Connecticut, and Louisiana. New Jersey, in the Northeast region, recorded the highest COVID-19 mortalities during the initial period (January-July), while Washington D.C. had the highest drug overdose mortalities during the same period (January-July). Comparing the drug overdose mortalities in 2019 and 2020, most of the states showed an increase as the pandemic progressed. Analysis of the Census Regions showed that states with the highest drug overdose mortalities coincided with the states with highest COVID-19 mortalities. Table I shows the top five states with the highest mortalities in both datasets. The states in bold are present in both datasets.

\section{Spatial Analysis to Study Co-Location}

There was a spatial correlation between drug overdose mortalities and COVID-19 mortalities in all the months that were studied (March-July 2020) except for the last month for which data was available (July). The spatial correlation between drug overdose mortalities and COVID-19 mortalities was weak positive for March and June (0.3 for both) and moderate positive for April and May (0.4 for both), while July showed a very weak positive correlation (0.1). Mortality hot spots with $>90 \%$ confidence levels for both causes of death

TABLE I Regional breakdown of the top five states with highest mortalities from DOD and the COVID-19 pandemic

\begin{tabular}{lcc}
\hline Regions & $\begin{array}{c}\text { Top } 5 \text { locales per region } \\
\text { for overdose mortality }\end{array}$ & $\begin{array}{c}\text { Top } 5 \text { locales per region } \\
\text { for COVID-19 mortality }\end{array}$ \\
\hline Northeast & CT, MA, NJ, PA, RI & CT, MA, NJ, NY, RI \\
Midwest & IL, IN, MI, MO, OH & IA, IL, IN, MI, OH \\
West & AZ, CO, NM, NV, WA & AZ, CA, CO, NM, NV \\
South & DC, DE, MD, TN, WV & DC, DE, LA, MD, MS \\
\hline
\end{tabular}

Note: The states that overlap between the two datasets are in bold. are shown (Figure 2). Drug overdose mortality showed very little change during the months observed, but COVID-19 mortality changed hot spots month to month with the biggest change in July as southern states began to experience more deaths due to COVID-19.

\section{DISCUSSION}

The study showed that the COVID-19 pandemic was associated with increased mortality rates over time in most states. An examination of drug overdose mortality in the study period showed that the hot spots initially followed the COVID-19 hot spots, but in July, COVID-19 mortality shifted to the southern belt of the United States. A limitation of this study is that full drug mortality data for 2020 was not available. Therefore, this analysis should be repeated when full 2020 drug overdose mortality data is released by the CDC.

\section{CONCLUSION}

The study showed that drug overdose deaths increased during the COVID-19 pandemic. Although there was a moderate to weak positive spatial correlation between the two types of mortalities in the initial months, the COVID-19 mortalities shifted to the southern region in July. Drug overdose mortality data was not available beyond July 2020 to see whether those mortality rates also followed the same regional pattern. Other studies suggest that COVID-19 affected the lives of people both socially and economically, causing distress (Carrasco, 2021), which may have increased drug usage or perhaps reduced access to drug treatment and social service supports (Mann, 2021; RHIhub, 2021). Meanwhile, the COVID19 death rates fluctuated by state depending on local weather, testing, treatment, and policies such as mask mandates and closure of businesses. Early in the pandemic, strict lockdowns and quarantines may have made substance use disorder treatments hard to access (Volkow, 2020). The shifting treatment
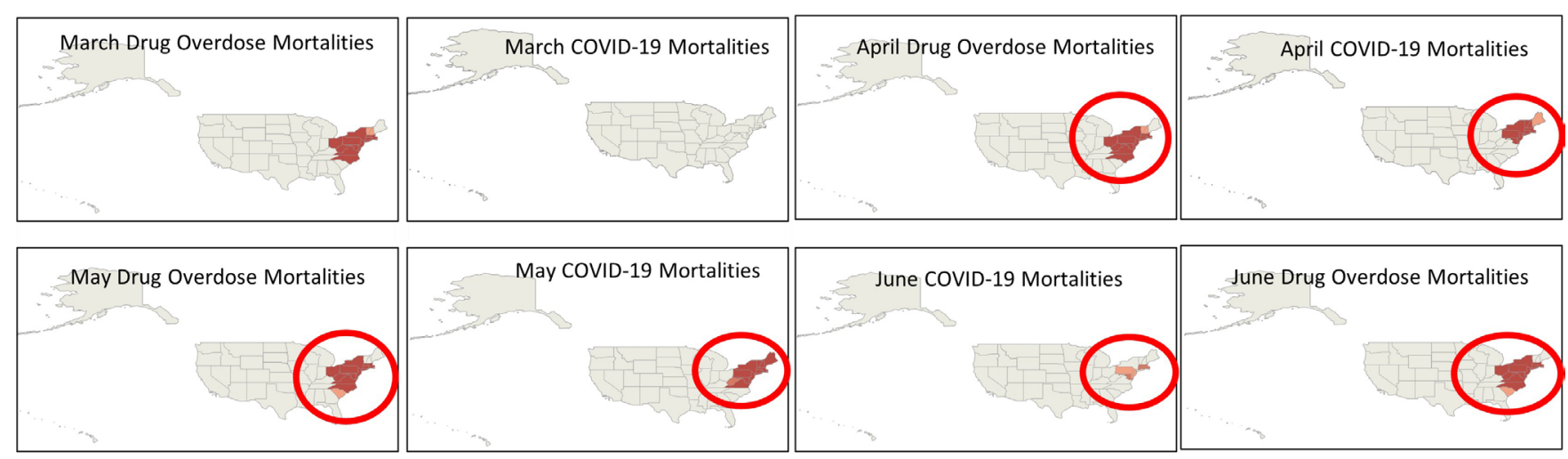

June Drug Overdose Mortalities
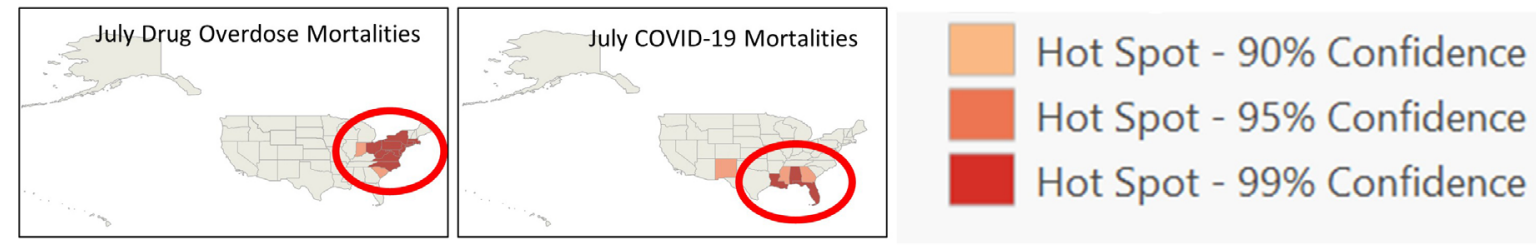

FIGURE 2 Monthly hot spot analysis of DOD and COVID-19 mortalities. DOD = drug overdose deaths. 
to available online providers and the lack of usual in-person meetings may also have had effects on patients who did not trust unfamiliar providers and treatment methods (Weiner, 2020). Another reason for many patients to not seek in-person substance use disorder treatment during the pandemic was the fear of contracting COVID-19 (Weiner, 2020). However, towards the end of 2020, policy changes helped those with substance use disorder by allowing changes in reimbursement rules, allowing telehealth, combining telemedicine with street access to people with limited access to internet, expanding access to medications for substance use disorders, and other policy changes such as suspending certain waiver requirements to provide greater access to buprenorphine (Baumgartner \& Radley, 2021; Volkow, 2020; Weiner, 2020). This may affect the co-location of drug overdose mortalities and COVID-19 mortalities. Further analysis should be continued when full 2020 drug overdose mortality data are released by the CDC.

\section{Recommendations}

Once the final data from 2020 are available, it will be important to see whether the hot spots for drug-related deaths moved to southern regions along with the hot spots for COVID-19related deaths. It is important to carry out policy analysis to determine whether the changes influenced by COVID-19 to improve access to drug treatment had a beneficial effect on overdose mortality rates. These changes in rules for access to drug treatment may be continued after the pandemic is over in order to improve delivery of care and services to those at risk for DOD, thereby preventing more of these deaths.

Evidence-based prevention and response strategies, including substance use disorder treatment and overdose prevention and response efforts focused on polysubstance use, must be adapted to address the changing drug overdose epidemic.

\section{Limitations}

The data availability was the biggest limitation for this study because of the $>6$-month lag in availability of drug overdose mortality data. Drug overdose data from 2020 were available at the state level but not at the county level, which also hindered the timely identification of hot spots within states that might have helped locales to concentrate service delivery where needed. In addition, the drug overdose mortality data did not include any demographic information that might have allowed study of the correlation between COVID-19 mortalities and drug overdose mortalities for different segments of the population.

\section{CONFLICT OF INTEREST DISCLOSURES}

The authors have no actual or potential conflicts of interest to declare.

\section{AUTHOR AFFILIATIONS}

*Buchholz High School, Gainesville, FL, USA; ${ }^{+}$Professor Emerita, University of Florida College of Medicine, Gainesville, FL, USA

\section{REFERENCES}

American Medical Association Issue Brief. (2021). Nation's drugrelated overdose and death epidemic continues to worsen. AMA Advocacy Resource Center, updated August 4, 2021. https://www.ama-assn.org/system/files/issue-brief-increases-inopioid-related-overdose.pdf
Baumgartner, J. C., \& Radley, D. C. (2021, March 25). The spike in drug overdose deaths during the COVID-19 pandemic and policy options to move forward. The Commonwealth Fund. https://www. commonwealthfund.org/blog/2021/spike-drug-overdose-deathsduring-covid-19-pandemic-and-policy-options-move-forward

Carrasco, J. (2021, March 15). Latinos grapple with opioid overdose rise as pandemic triggers surge in U.S. use. Noticias Telemundo, NBC. https://www.nbcnews.com/news/latino/latinos-grapple-opioidoverdose-rise-covid-pandemic-triggers-surge-us-rcna415

Centers for Disease Control and Prevention (CDC). (202la). Drug overdose deaths. Centers for Disease Control and Prevention, National Center for Injury Prevention and Control, Mar. 3. https://www.cdc.gov/ drugoverdose/data/statedeaths.html

CDC. (2021 b). Drug overdose deaths increased during the COVID-19 pandemic. Centers for Disease Control and Prevention, National Center for Injury Prevention and Control, May 11. https://www. cdc.gov/drugoverdose/pubs/featured-topics/save-lives-now.html

Cicero, T. J., Ellis, M. S., Surratt, H. L., \& Kurtz, S. P. (2014). The changing face of heroin use in the United States: a retrospective analysis of the past 50 years. JAMA Psychiatry, 71(7), 821-826.

Czeisler, M. E., Lane, R. I., Petrosky, E., Wiley, J. F., Christensen, A., Niai, R., Weaver, M. D., Robbins, R., Facer-Childs, E. R., Barger, L. K. Czeisler, C. A., Howard, M. E., \& Rajaratnam, S. M. W. (2020, August 14). Mental health, substance use, and suicidal ideation during the COVID-19 pandemic-United States, June 24-30, 2020. Weekly, 69(32);1049-1057. https://www.cdc.gov/mmwr/volumes/69/ $\mathrm{wr} / \mathrm{mm} 6932 \mathrm{al} . \mathrm{htm}$

Department of Health and Environmental Control (DHEC). (2020, December 211. Increase in fatal drug overdoses across the United States driven by synthetic opioids before and during the COVID-19 pandemic. South Carolina Department of Health and Environmental Control (DHEC) Health Advisory, 10482-DHA-12-21-2020-OPIOID. https://scdhec.gov/sites/default/files/media/document/10482DHA-12-21-2020-OPIOID.pdf

Ghertner, R., \& Groves, L. (2018, September 11). The opioid crisis and economic opportunity: geographic and economic trends. ASPE Research Brief, Office of the Assistant Secretary for Planning and Evaluation, U.S. Department of Health and Human Services. https://aspe. hhs.gov/sites/default/files/private/pdf/25926l/ASPEEconomic OpportunityOpioidCrisis.pdf

Johnson, C. K., Rodriguez, O. R., \& Kastanic, A. (2021, June 14). As US COVID-19 death toll nears 600,000, racial gaps persist. AP News. https://apnews.com/article/baltimore-california-coronaviruspandemic-race-and-ethnicity-health-341950a902affc65 1dc268dbabd83264

Mann, B. (2021, April 21). Overdose deaths surged in pandemic, as more drugs were laced with fentanyl. Delaware Public Media. https:// www.delawarepublic.org/post/overdose-deaths-surged-pandemicmore-drugs-were-laced-fentanyl

National Vital Statistics System (NVSS). (2021). Provisional drug overdose death counts, CDC, May 12. https://www.cdc.gov/nchs/nvss/vsrr/ drug-overdose-data.htm

RHIhub, Rural Health Information Hub. (2021). Substance use and misuse in rural areas. Accessed August 14. https://www.ruralhealthinfo.org/ topics/substance-use

Stephenson, J. (2020). Drug overdose deaths head toward record number in 2020, CDC Warns. JAMA Health Forum 1(10):e201318. https:// doi.org.10.1001/jamahealthforum.2020.1318.

Tripathi, N. (2019, September 28-October 2). Deaths by drugs: A spatiotemporal analysis of the drug epidemic in the United States. GIS-Pro 2019: Urban and Regional Information Systems Association (URISA), New Orleans, LA, USA. 
PANDEMIC MEETS EPIDEMIC: COVID-19 \& OVERDOSE DEATHS, Tripathi \& Hardt

Volkow, N. (2020, September14). Addressing the unique challenges of COVID-19 for people in recovery. National Institute on Drug Abuse (NIDA). https://www.drugabuse.gov/about-nida/noras-blog/ 2020/09/addressing-unique-challenges-covid-19-peoplein-recovery

Wagner, J., Neitzke-Spruill, L., O'Connell, D., Highberger, J., Martin, S. S., Walker, R., \& Anderson, T. (2019). Understanding geographic and neighborhood variations in overdose death rates. Journa of Community Health, 44, 272-283. https://doi.org/10.1007/ s10900-018-0583-0

Weiner, S. (2020, July 27). COVID-19 and the opioid crisis: When a pandemic and an epidemic collide. Healthcare, Association of American Medical Colleges (AAMC). https://www.aamc.org/news-insights/ covid-19-and-opioid-crisis-when-pandemic-and-epidemic-collide 